\title{
Changing Indications for Penetrating Keratoplasty in Bahrain in a Tertiary Referral Centre
}

This article was published in the following Dove Press journal: Clinical Ophthalmology

\section{Nada Al-Yousuf,' Ebtisam Al Alawi, ${ }^{2}$ Abdulhameed Mahmood, (iD ${ }^{3}$ Amani Alzayani, ${ }^{4}$ Hajer Al Sawad, ${ }^{4}$ Hasan Alsetri, ${ }^{5}$ Jalal Al-Mousawi, (iD) ${ }^{6}$ Khatoon $\mathrm{Ali}^{4}{ }^{4}$ Maryam Al Khayat, ${ }^{4}$ Reem Naser ${ }^{4}$ \\ 'Department of Ophthalmology, King Abdulla Medical City, Manama, Bahrain; ${ }^{2}$ The Eye Center, Manama, Bahrain; ${ }^{3}$ Department of Ophthalmology, Prince Sultan Military Medical City, Riyadh, Saudi Arabia; ${ }^{4}$ Department of Ophthalmology, Salmaniya Medical Complex, Manama, Bahrain; ${ }^{5}$ Department of Chemistry and Biochemistry, University of California, Los Angeles, CA, USA; ${ }^{6} \mathrm{Al}$-Mousawi Specialist Center, Manama, Bahrain}

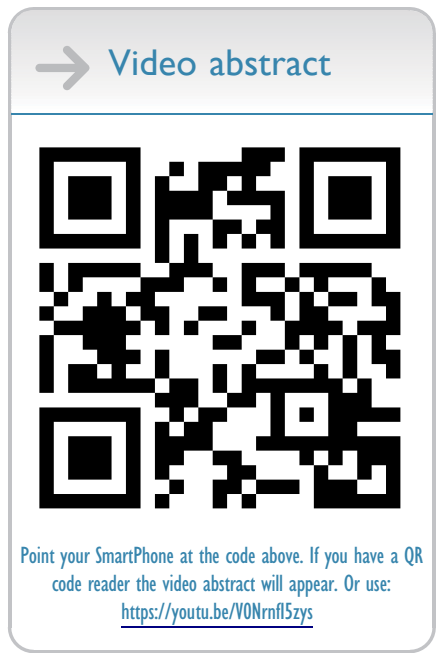

Correspondence: Nada Al-Yousuf Department of Ophthalmology, King Abdulla Medical City, P.O. Box 2667I, Adliya, Bahrain

Tel +973 7731007l

Fax +973 77310001

Email nyousuf10@gmail.com
Purpose: To study the changing indications for Penetrating keratoplasty in Bahrain and to compare them with published data.

Patients and Methods: A Retrospective review of available records of patients who underwent penetrating keratoplasty at a tertiary center in Bahrain (1996-2015). The trend of each indication was analyzed. The study was subdivided into three periods for correlation purposes. Pearson Coefficient $r$ and the $p$ values were used for interpretation of data. The results were compared with similar studies.

Results: A total of 298 patients underwent keratoplasty in the study period, which is from 1996 until 2015 (missing data 2009-2011). Keratoconus was found to be the leading indication, accounting for $33 \%$ of the total cases, followed by trachoma $27 \%$, followed by aphakic and pseudophakic bullous keratopathies 13\%. Trachoma showed a statistically significant decreasing trend $(\mathrm{p}<0.001)$, Keratoconus had an increasing trend $(\mathrm{p}<0.001)$. Bullous keratopathy showed an increasing trend $(\mathrm{p}=0.001)$ with an abrupt rise after 2012 . Conclusion: Corneal scarring due to old trachoma was the leading indication for keratoplasty 20 years ago in Bahrain. However, due to improvement of health awareness, hygiene, and the socioeconomic status, this has regressed with keratoconus becoming the leading indication from 2002 onwards. A surge of bullous keratopathy was noted after 2012, placing it as the second commonest indication. This may be due to the introduction of phacoemulsification technique for cataract surgery, and perhaps because the nature of the institute being a teaching hospital. Keratoconus is the leading indication and showed an increasing trend. It is recommended to perform a keratoconus screening program for early detection and prevention.

Keywords: keratoconus, bullous keratopathies, corneal graft, indications, cornea transplant, trachoma

\section{Introduction}

Corneal blindness is the third cause of blindness in the world, after cataract and glaucoma. It affects 4 million people worldwide. ${ }^{1,2}$ Corneal transplantation is the most effective treatment for blinding corneal disorders, ${ }^{2}$ and considered the most common transplant in the world. ${ }^{3}$ The epidemiology of corneal blindness differs geographically, depending on the spectrum of disorders in different parts of the world. ${ }^{4}$ Similarly, the trends of keratoplasty indications show variations both geographically and historically. This is attributed to changes in socioeconomic status, level of education, public awareness, healthcare availability, and advances in medical and surgical management. Bullous keratopathies and Fuch's endothelial dystrophies were reported as leading indications for keratoplasty in developed 
countries. ${ }^{5-8}$ Microbial keratitis was reported as the leading indication for penetrating keratoplasty in developing countries. $^{9-12}$

Surgical techniques of keratoplasty have evolved. ${ }^{7,8,13-17}$ Despite the growing interest in both lamellar and endothelial keratoplasties over the last 10 years, penetrating keratoplasty is still frequently performed, with a number of 17,409 grafts in USA in $2019 .^{18}$

Since corneal blindness is one of the most important causes of blindness in the region, ${ }^{16,19}$ understanding the indications for keratoplasty, would give insight to the underlying disease processes. Therefore, this would help placing preventive measures for such diseases. We report herewith the indications for penetrating keratoplasty in the Kingdom of Bahrain, with emphasis on the changing trends.

\section{Patients and Methods}

A retrospective review of patients' records who underwent keratoplasty at Salmaniya Medical Complex, a tertiary referral center in the Kingdom of Bahrain, was done. Approval from the research ethical committee for secondary care of Ministry of Health, was obtained in the meeting number 417. Patients' consent to review their medical records was not required by the research ethical committee. This is due to the retrospective nature of the study. The patients' data were maintained confidential. The study was carried out in accordance with the tenets of the declaration of Helsinki.

The primary indication for each surgery was recorded. The indication of keratoplasty consisted of the surgeons' clinical diagnoses prior to surgery, and confirmed by histopathology. In cases of multiple keratoplasties, the diagnosis is considered as "regraft", regardless of the initial diagnosis for the graft. Bullous keratopathy included both aphakic and pseudophakic bullous keratopathies, which refer to corneal decompensation following cataract surgery. Microbial keratitis included patients with bacterial, fungal, or acanthamoeba keratitis, whether underwent therapeutic keratoplasty, or those who eventually developed corneal scars with negative cultures. Herpetic keratitis diagnosis was based on documentation and treatment for herpes simplex viral infection, resulting in corneal scars, in the absence of active infection. Old trachoma category refers to patients with corneal scars with features of previous trachoma. Corneal dystrophies included stromal and endothelial dystrophies.

For administrative purposes, we had no access to data from 2009 to 2011. Therefore, the indications in this time period were not studied. For comparison and analytical purposes, the data were divided in three different time periods. The first one is from 1996 to 2002, and is referred to as the early study period. The second is from 2003 to 2008 , and is referred to as the intermediate study period. The third period is between 2012 and 2015, and is referred to as the latest study period. The three time periods represent the development in the socioeconomic status and the advancement in health care services in Kingdom of Bahrain, respectively. The trends for all indications were studied in the overall time period.

Pearson Coefficient $r$ and linear regression tests were used to study changes in the trends of keratoplasty indications. $P$ values were used to study the statistical significance of the trends. A $P$ value less than 0.05 is considered statistically significant.

\section{Results}

A total of 298 patients underwent keratoplasty during the total study period, which is from 1996 to 2015. This number does not include the missing data from 2009 to 2011. Keratoconus was found to be the leading indication forming $33 \%$, followed by old trachoma $27 \%$, followed by aphakic and pseudophakic bullous keratopathy 13\%. Other indications were regrafts $7 \%$, microbial keratitis $6 \%$, trauma 5\%, herpetic keratitis 4\%, corneal dystrophies 3\% and corneal melt 2\% (Figure 1).

During the early study period, 104 cases were done. Old trachoma used to be the leading indication forming $41 \%$, followed by keratoconus $22 \%$, microbial keratitis $7.6 \%$, trauma $6.7 \%$, bullous keratopathies $6.7 \%$, herpetic keratitis $5.7 \%$, regrafts $4.8 \%$, corneal dystrophies $3.8 \%$, and corneal perforation $0.9 \%$ (Figure 2 ). In the intermediate study period, 95 cases were done. Keratoconus became the leading

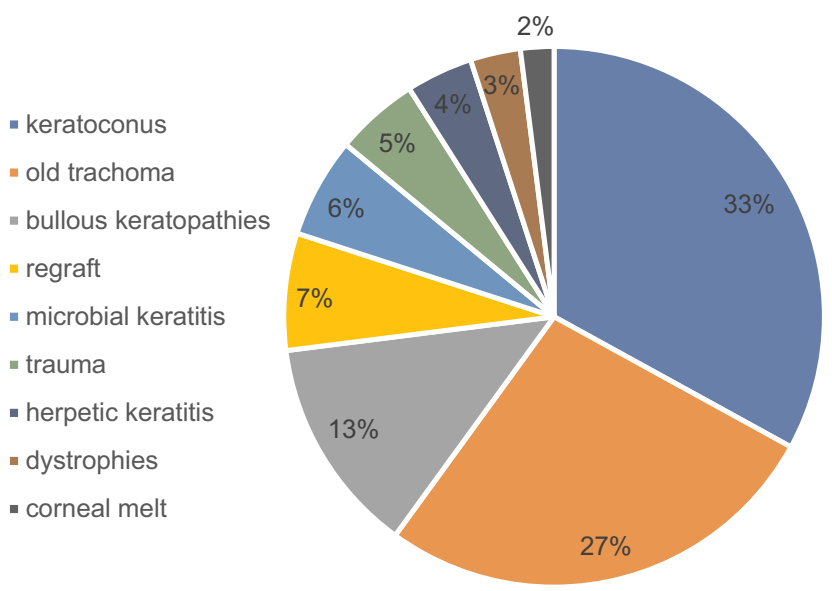

Figure I Indications of penetrating keratoplasty in Kingdom of Bahrain (199620I5). Keratoconus is the leading indication followed by old trachoma and bullous keratopathies. 
$1996-2002$

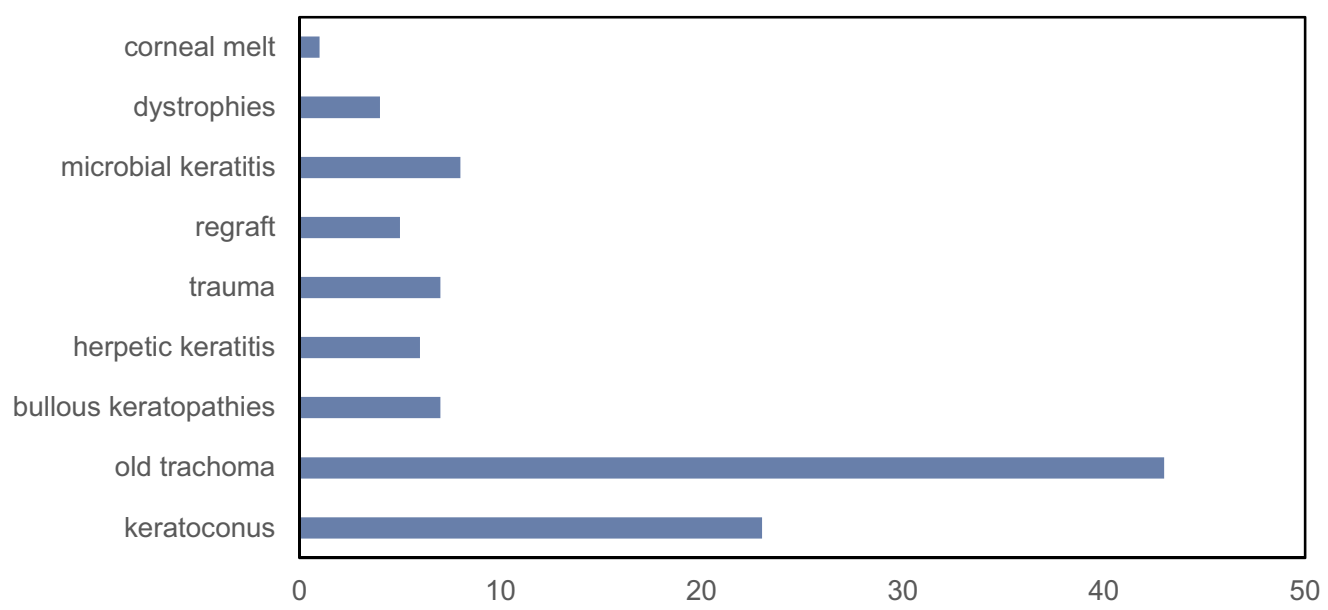

Figure 2 Old trachoma used to be the leading indication for penetrating keratoplasty during the early study time period.

$2003-2008$

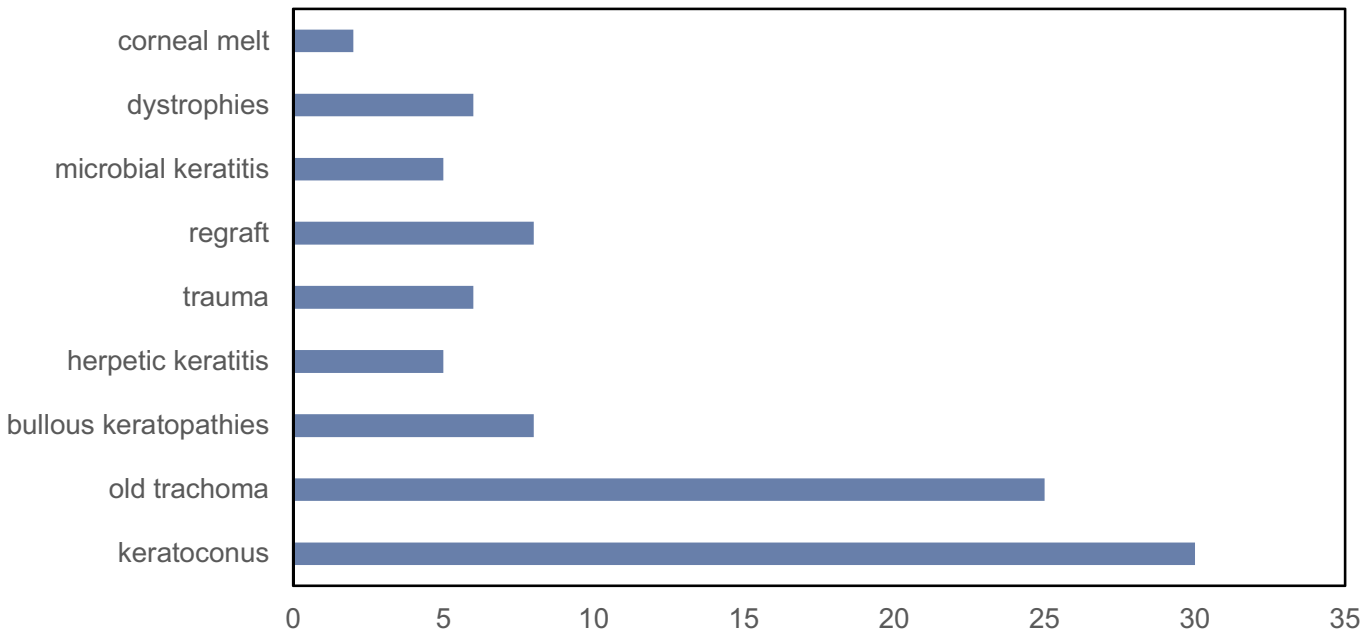

Figure 3 During the intermediate study time period, keratoconus took the lead as the commonest indication for penetrating keratoplasty.

indication forming $32.6 \%$, followed by old trachoma $26.3 \%$, bullous keratopathies $9.4 \%$, regrafts $8.4 \%$, trauma $6.3 \%$, microbial keratitis $5.2 \%$, herpetic keratitis $5.2 \%$, and corneal perforation $3.1 \%$ (Figure 3). In the latest study period, 99 cases were done. Keratoconus continued to be the commonest indication forming $41 \%$, followed by bullous keratopathies $22 \%$. Other indications were old trachoma $11 \%$, regrafts $7 \%$, microbial keratitis $6 \%$, trauma $4 \%$, corneal perforation $4 \%$, herpetic keratitis $3 \%$ and Fuchs endothelial dystrophy $1 \%$ (Figure 4).

Studying the trends of each indication separately during the total study period, revealed that there is a significant decreasing trend in old trachoma, which has reduced from
$41 \%$ in the early study period to $26 \%$ in the intermediate study period, then to $11 \%$ in the latest study period. This reduction in trend is statistically significant $(\mathrm{p}<0.001)$ (Figure 5).

Keratoconus, however, showed an increasing trend. It increased from $22 \%$ in the early study period, then becoming the leading indication forming $33 \%$ and $41 \%$ in the intermediate and latest study periods, respectively. This increase in trend is statistically significant $(\mathrm{p}<0.001)$ (Figure 6).

The trend for bullous keratopathies was increasing. It used to be $6.7 \%$ in the early study period. It has then increased forming $9.4 \%$ in the intermediate study period, then increased to $22 \%$ in the latest study period. This increase in trend is statistically significant $(p=0.001)$ (Figure 7). 


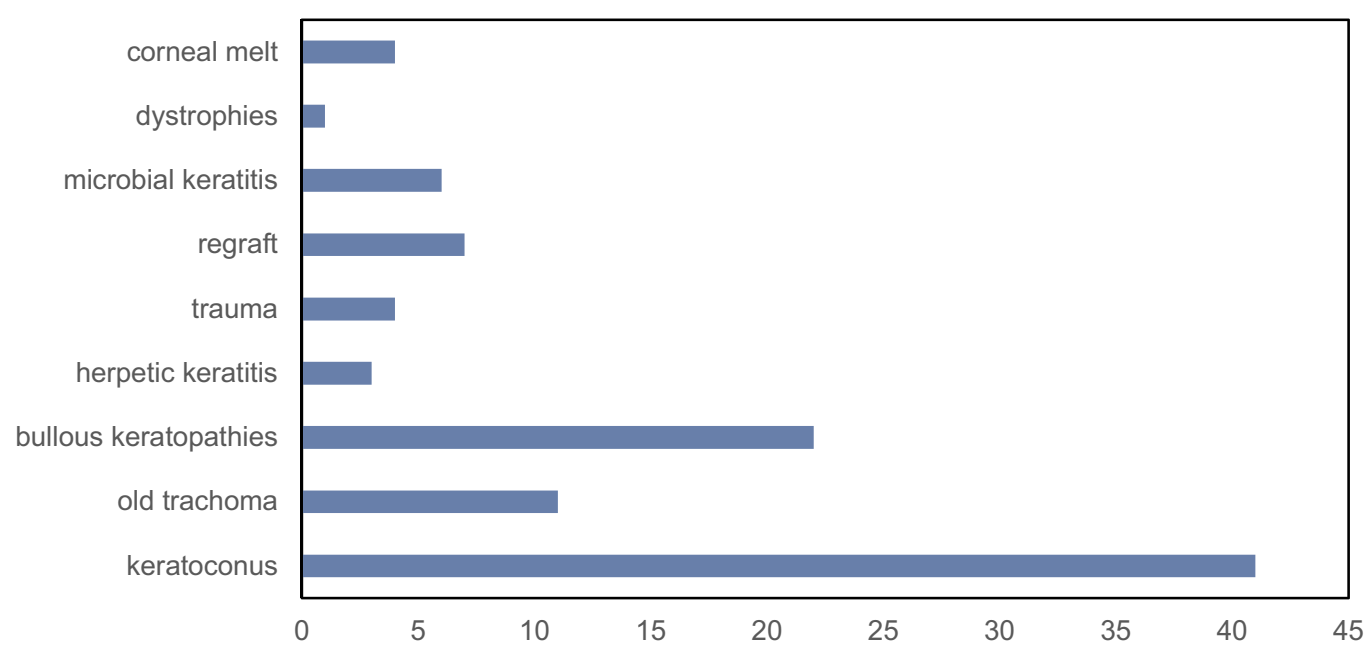

Figure 4 During the latest study time period, keratoconus continued to be the leading indication for penetrating keratoplasty, while bullous keratopathies emerged as the second leading indication.

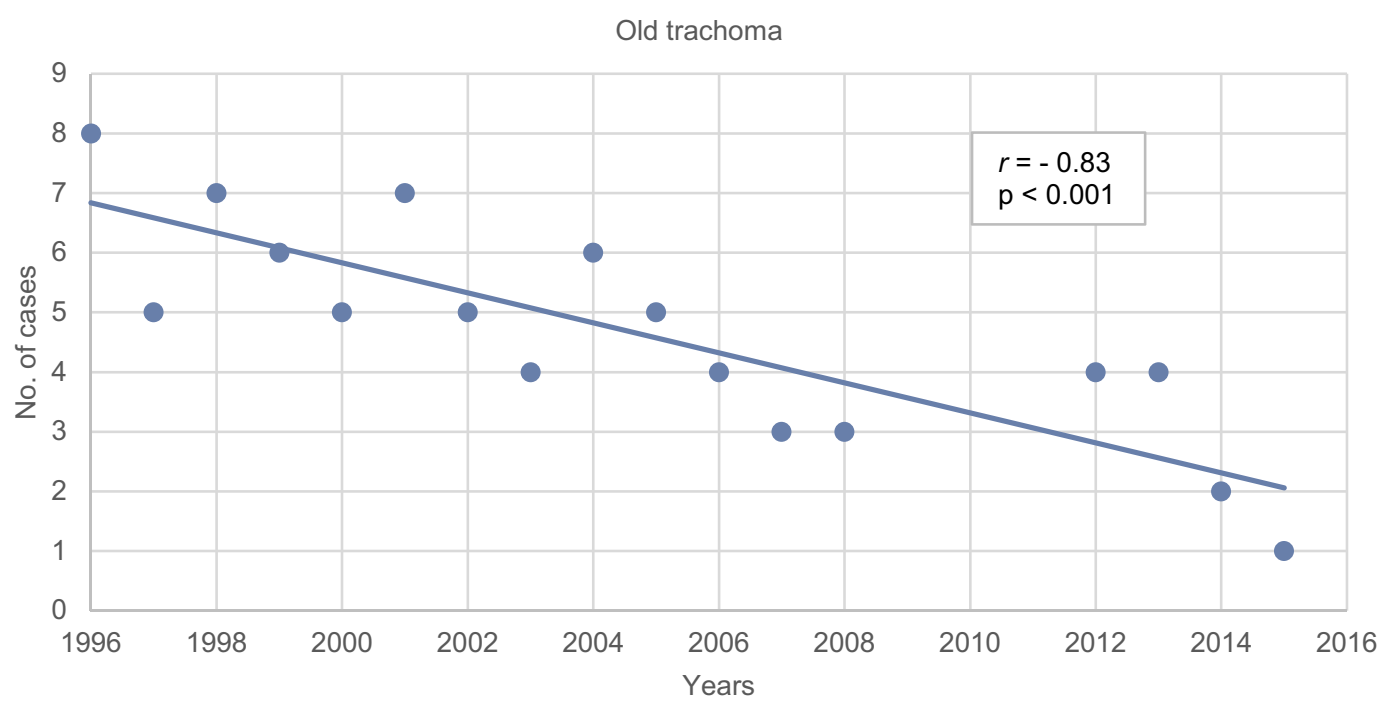

Figure 5 Old trachoma as an indication for penetrating keratoplasty showed a statistically significant reducing trend using regression analysis ( $\mathrm{P}<0.00 \mathrm{I}$ ). The correlation coefficient $r$ measures the closeness of fit of data to the regression line.

Regrafting showed an overall increase in the trend over the whole study period. This increase was not statistically significant $(\mathrm{p}=0.06)$. Other indications such as trauma, corneal dystrophies, herpetic keratitis, microbial keratitis and corneal melts were fluctuating over the study periods, showing no correlations and no significant trends (Figure 8).

\section{Discussion}

This study identified the leading indications for penetrating keratoplasty over a dynamic period of time. The study time period demonstrated advancement in socioeconomic status that reflected in changes in penetrating keratoplasty indications. A better understanding of the changing trends of these indications was obtained, when studied into different time periods. In the early study period, old trachoma was the leading indication followed by keratoconus. This changed over the years, with the development in social welfare, and advancement of health care. Keratoconus became the leading indication in the latest study period, followed by bullous keratopathies. Keratoconus was reported as the leading indication for penetrating keratoplasty in the eastern province of Saudi Arabia, followed by bullous keratopathy. ${ }^{19}$ This is 


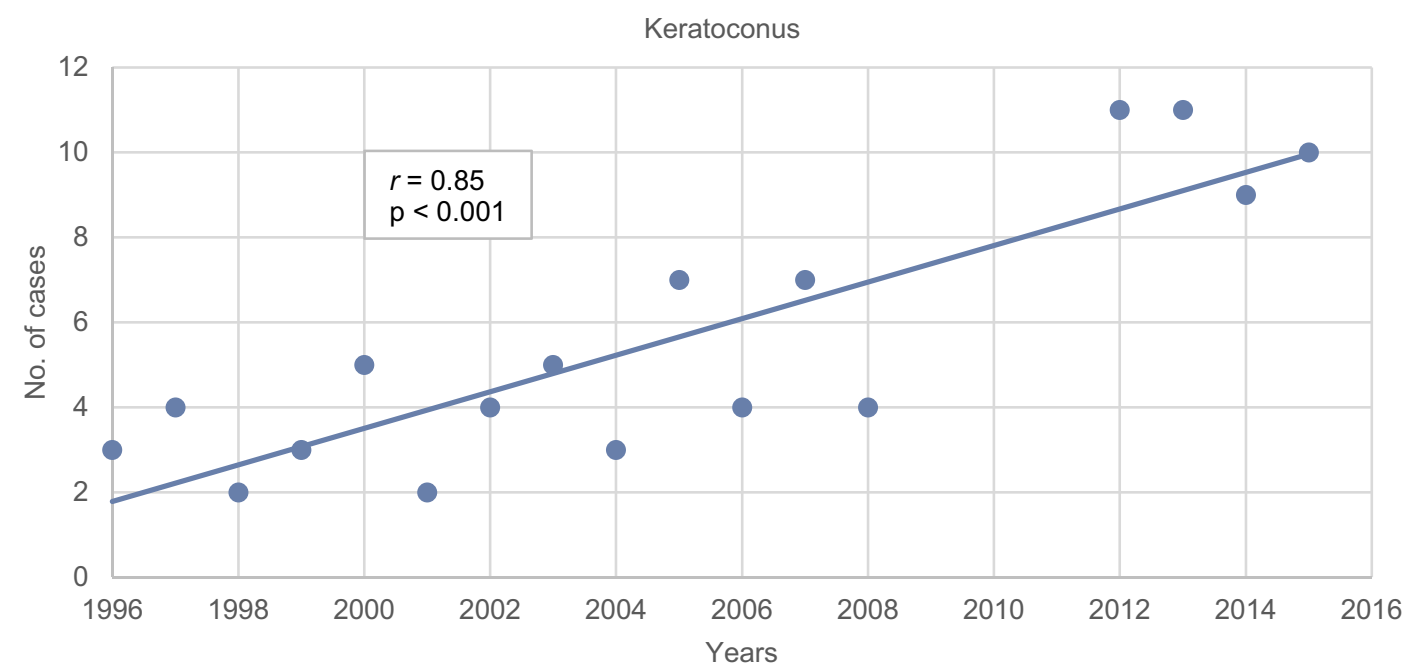

Figure 6 Keratoconus as an indication for penetrating keratoplasty showed a statistically significant increasing trend using regression analysis $(p<0.00 \mathrm{I})$. The correlation coefficient $r$ measures the closeness of fit of the data to the regression line.

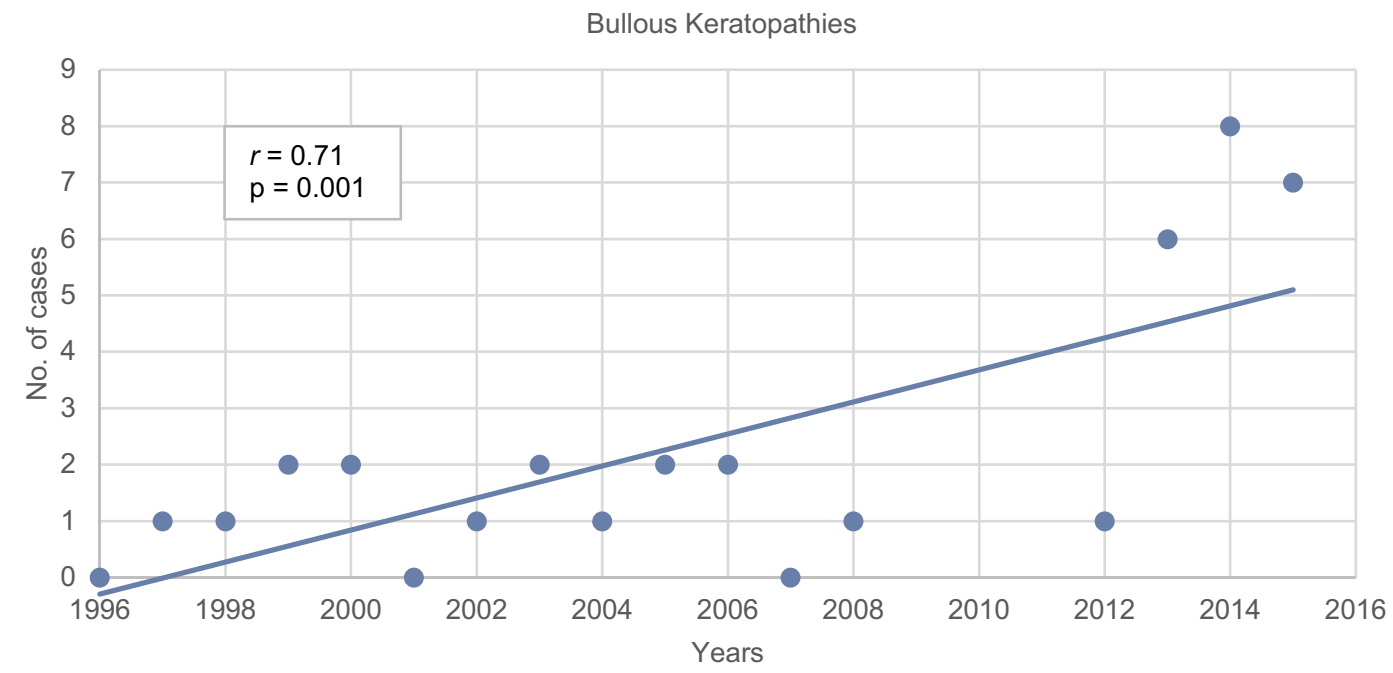

Figure 7 Bullous keratopathies as an indication for penetrating keratoplasty showed a statistically significant increasing trend using regression analysis ( $\mathrm{P}=0.00 \mathrm{I}$ ). The correlation coefficient $r$ measures the closeness of fit of the data to the regression line.

consistent with the results of our study. Several other studies from Saudi Arabia also implicated Keratoconus as the leading indication for keratoplasty. ${ }^{20-22}$

Interestingly, the changing trends in indications of keratoconus and old trachoma, were similar to those reported in Saudi Arabia by Al-Towerki et al. ${ }^{22}$ We believe these trends could be attributed to the significant improvement in socioeconomic conditions of the Bahraini and Saudi population over the last few decades. This led to the elimination of active trachoma, thus decreasing the number of significant corneal scars leading to penetrating keratoplasty. Keratoconus being a leading indication in our study, is consistent with several studies in the Middle East, where genetic and environmental factors, have been implicated as contributing factors. ${ }^{23-28}$

To this date, Trachoma remains the most common indication for penetrating keratoplasty in Ethiopia, ${ }^{11}$ as the prevalence of active trachoma in some parts of Sub-Saharan Africa is among the highest in the globe. ${ }^{29,30}$

Studies from several Asian countries have shown lower percentage of keratoconus compared to our study. It was $7 \%$ in Nepal, ${ }^{31} 11.2 \%$ in China, ${ }^{32} 13.5 \%$ in $\mathrm{Japan}^{33}$ and $1.9 \%$ in Vietnam. $^{9}$ 

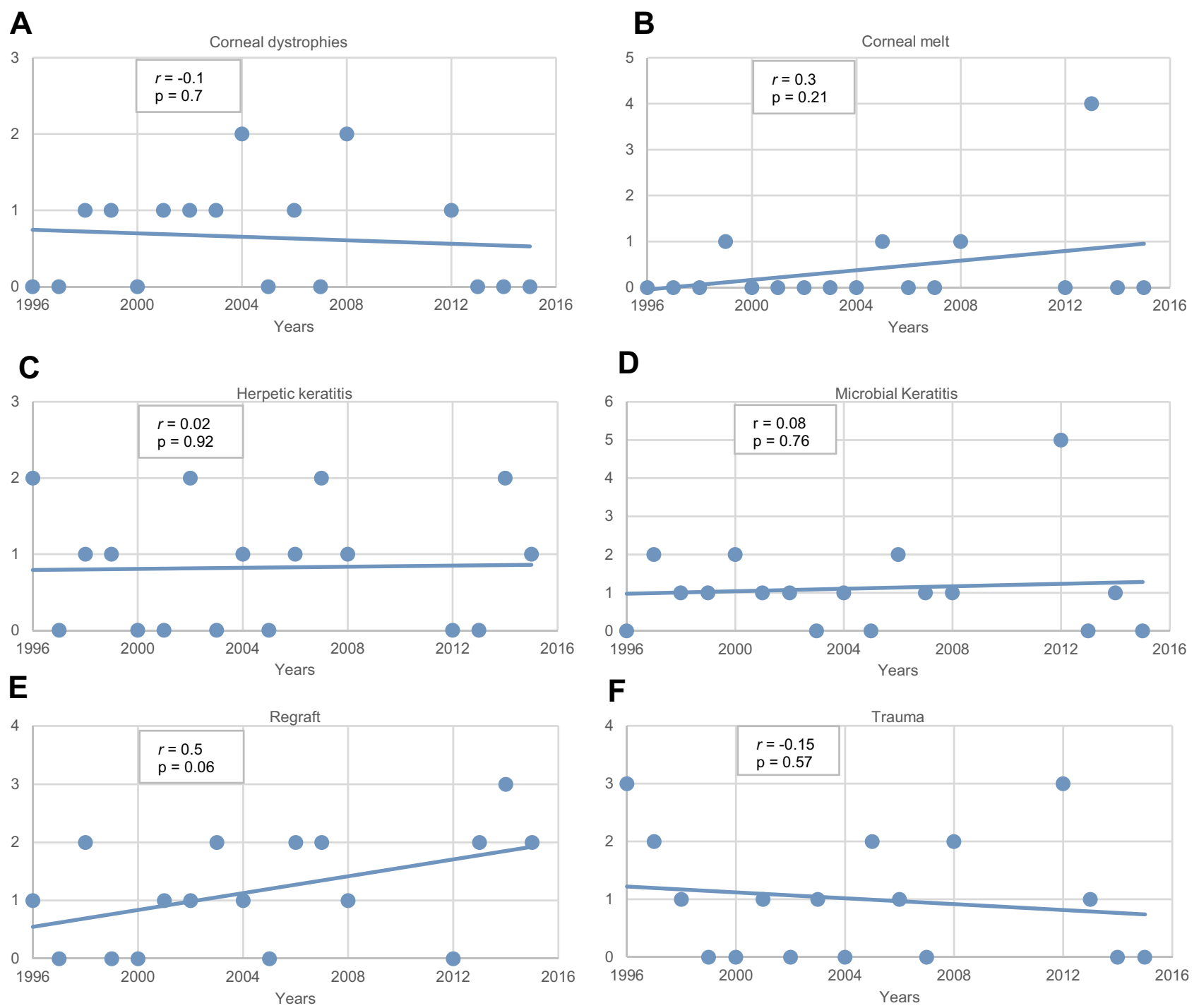

Figure 8 Graphs of the trends of $(\mathbf{A})$ corneal dystrophies, (B) corneal melt, (C) herpetic keratitis, (D) microbial keratitis, (E) regrafts, and (F) trauma. The vertical axes represent the number of keratoplasty cases. Trends of corneal dystrophies, corneal melts, herpetic keratitis, microbial keratitis and trauma were fluctuating throughout the study period and did not show a statistically significant trend. Regrafting showed an increasing trend, it was not statistically significant.

While microbial keratitis was among the least common indications in our study (6\%), it was the most common indication in Nepal (40.9\%), ${ }^{31}$ China $(56.2 \%)^{32}$ and Vietnam (48.2\%). ${ }^{9}$

In Japan and Singapore, which both have higher socioeconomic statuses compared to other Asian countries, the most common indication for penetrating keratoplasty was pseudophakic bullous keratopathy $(37.6 \%$ and $23.4 \%$, respectively). ${ }^{33,34}$ This indicates that the higher prevalence of microbial keratitis in other Asian countries, is more likely to be associated with socioeconomic statuses, rather than demographic or genetic factors.
Despite continuing improvements in cataract surgery instrumentation, aphakic and pseudophakic bullous keratopathies remains important indications for keratoplasty. It was the second most common in the latest period of our study (22\%), a percentage that is comparable to those reported in USA (27\%) and Canada (17.4\%). ${ }^{7,8,35}$ Both aphakic and pseudophakic bullous keratopathies emerged as the second leading indication in the latest study period. This is explained by the significant shift to phacoemulsification, and the nature of our institution being a teaching hospital. 
Both deep anterior lamellar keratoplasty (DALK), and Descemet Stripping Automated Endothelial keratoplasty (DSAEK) techniques, were introduced in the Kingdom of Bahrain in 2016. A study looking at the changes in keratoplasty techniques is underway. Moreover, with more DALK being performed, we expect regrafting as an indication for keratoplasty to regress in future studies.

\section{Conclusion}

This study highlights that keratoconus is the leading indication for penetrating keratoplasty in Kingdom of Bahrain. Conducting screening programs is recommended to detect keratoconus early, prevent deterioration and reduce the need for keratoplasty.

\section{Disclosure}

The authors report no conflicts of interest in this work. They have no financial interest or other conflicts of interest. The abstract of this paper was presented in part at the 24th ESCRS winter meeting as a poster presentation.

\section{References}

1. Resnikoff S, Pascolini D, Etya'ale D, et al. Global data on visual impairment. Bull World Health Organ. 2004;82:11. doi:10.1590/ S0042-96862004001100009

2. Lamm V, Hara H, Alex Mammen A, Dhaliwal D, Cooper D. Corneal blindness and xenotransplantation. Xenotransplantation. 2014;21 (2):99-114. doi:10.1111/xen.12082

3. Gain P, Jullienne R, He Z, et al. Global survey of corneal transplantation and eye banking. JAMA Ophthalmol. 2016;134(2):167-173. doi:10.1001/jamaophthalmol.2015.4776

4. Whitcher J, Srinivasan M, Upadhyay M. Corneal blindness: a global perspective. Bull World Health Organ. 2001;79(3).

5. Bigan G, Puyraveau M, Saleh M, et al. Corneal transplantation trends in France from 2004 to 2015: a 12-year review. Eur J Ophthalmol. 2018;28(5):535-540. doi:10.1177/1120672118762224

6. Keenan TD, Jones MN, Rushton S, Carley FM. Trends in the indications for corneal graft surgery in the United Kingdom: 1999 through 2009. Arch Ophthalmol. 2012;130(5):621-628. doi:10.1001/ archophthalmol.2011.2585

7. Park C, Lee J, Gore P, Lim C, Chuck R. Keratoplasty in the United States. A 10-year review from 2005 through 2014. Ophthalmology. 2015;122(12):2432-2442. doi:10.1016/j.ophtha.2015.08.017

8. Tan J, Holland S, Dubord P, Moloney G, McCarthy M, Yeung S. Evolving indications for and trends in Keratoplasty in British Columbia, Canada, from 2002 to 2011: a 10-year review. Cornea. 2014;33(3):252-256. doi:10.1097/ICO.0000000000000066

9. Dong PN, Han TN, Aldave AJ, Chau HTM. Indications for and techniques of keratoplasty at Vietnam National Institute of Ophthalmology. Int $J$ Ophthalmol. 2016;9(3):379-383. doi:10.18240/ijo.2016.03.09

10. Raj A, Gupta N, Dhasmana R, Nagpal R, Bahadur H, Maitreya A. Indications and visual outcome of penetrating keratoplasty in tertiary eye care institute in Uttarakhand. J Clin Diagn Res. 2016;10:1-4.

11. Ayalew M, Tilahun Y, Holsclaw D, et al. Penetrating keratoplasty at a tertiary referral center in Ethiopia: indications and outcomes. Cornea. 2017;36(6):665-668. doi:10.1097/ICO.0000000000001190
12. Dasar L, Pujar C, Gill KS, Patil M, Salagar M. Indications of penetrating keratoplasty in Southern India. $J$ Clin Diagn Res. 2013;7(11):2505-2507. doi:10.7860/JCDR/2013/7030.3591

13. Boyton G, Woodward M. Evolving techniques in Corneal transplantation. Curr Surg Rep. 2015;2(2):1-13.

14. Rock T, Landerberger J, Bramkamp M, Bartz-Schmidt K, Rock D. The evolution of corneal transplantation. Ann Transplant. 2017;22:749-754. doi:10.12659/AOT.905498

15. Sun $X$, Zhai H, Cheng J, et al. Indications for penetrating keratoplasty and anterior lamellar keratoplasty during 2010-2017. Int J Ophthalmol. 2019;12:1878-1884. doi:10.18240/ijo.2019.12.10

16. Arfaj K, Yassin S, Beshri A, Al-Jindan M, Al-Tamimi E. Indications and techniques employed for keratoplasty in the eastern province of Saudi Arabia: 6 years of experience. Ann Saudi Med. 2015;35 (5):387-393. doi:10.5144/0256-4947.2015.387

17. Rock T, Bartz-Schmidt KU, Rock D. Trends in Corneal transplantation at the University Eye Hospital in Tubingen, Germany over the last 12 years: 2004-2015. PLoS One. 2018;13(6):1-12. doi:10.1371/ journal.pone. 0198793

18. Eye Bank Association of America. Eye Bank Association of America statistical report; 2019. Available from: https://restoresight.org/whatwe-do/publications/statistical-report/. Accessed March 27, 2021.

19. Arfaj K, Abdulqader R. Major indications for keratoplasty in the eastern province, Saudi Arabia. Saudi J Med Sci. 2014;2:173-177. doi:10.4103/1658-631X.142527

20. Omar N, Bou Chacra CT, Tabbara KF. Outcome of corneal transplantation in a private institution in Saudi Arabia. Clin Ophthalmol. 2013;7:1311-1318. doi:10.2147/OPTH.S43719

21. Wagoner MD, Gonnah ES, Al-Towerki AE; King Khaled Eye Specialist Hospital Cornea Transplant Study Group. Outcome of primary adult penetrating keratoplasty in a Saudi Arabian population. Cornea. 2009;28(8):882-890. doi:10.1097/ICO.0b013e31819b00d8

22. Al-Towerki AE, Gonnah E-S, Al-Rajhi A, Wagoner MD. Changing indications for corneal transplantation at the King Khaled Eye Specialist Hospital (1983-2002). Cornea. 2004;23(6):584-588. doi:10.1097/01.ico.0000121708.58571.5b

23. Assiri AA, Yousuf BI, Quantock AJ, et al. Incidence and severity of keratoconus in Asir province, Saudi Arabia. $\mathrm{Br} J$ Ophthalmol. 2005;89:1403-1406. doi:10.1136/bjo.2005.074955

24. Millodot M, Shneor E, Albou S, et al. Prevalence and associated factors of keratoconus in Jerusalem: a cross-sectional study. Ophthalmic Epidemiol. 2011;18:91-97. doi:10.3109/ 09286586.2011.560747

25. Waked N, Fayad AM, Fadlallah A, et al. Keratoconus screening in a Lebanese students' population. J Fr Ophtalmol. 2012;35:23-29. doi:10.1016/j.jfo.2011.03.016

26. Hashemi H, Beiranvand A, Khabazkhoob M, et al. Prevalence of keratoconus in a population-based study in Shahroud. Cornea. 2013;32:1441-1445. doi:10.1097/ICO.0b013e3182a0d014

27. Hashemi H, Khabazkhoob M, Yazdani N, et al. The prevalence of keratoconus in a young population in Mashhad, Iran. Ophthalmic Physiol Opt. 2014;34:519-527. doi:10.1111/opo.12147

28. Shneor E, Millodot M, Gordon-Shaag A, et al. Prevalence of keratoconus among young Arab students in Israel. Int J Keratoconus Ectatic Corneal Dis. 2014;3:9-14. doi:10.5005/jp-journals-10025-1070

29. Mwale C, Mumbi W, Funjika M, et al. Prevalence of trachoma in 47 administrative districts of Zambia: results of 32 population-based prevalence surveys. Ophthalmic Epidemiol. 2018;25:171-180. doi:10.1080/09286586.2018.1546880

30. Dézoumbé D, Djada D, Harba T, et al. Prevalence of trachoma in the Republic of Chad: results of 41 population-based surveys. Ophthalmic Epidemiol. 2018;25:143-154. doi:10.1080/09286586. 2018.1546877

31. Bajracharya L, Gurung R, Demarchis EH, Oliva M, Ruit S, Tabin G. Indications for keratoplasty in Nepal: 2005-2010. Nepal J Ophthalmol. 2013;5(2):207-214. doi:10.3126/nepjoph.v5i2.8730 
32. Wang JY, Xie LX, Song XS, Zhao J. Trends in the indications for penetrating keratoplasty in Shandong, 2005-2010. Int J Ophthalmol. 2011;4(5):492-497. doi:10.3980/j.issn.2222-3959.2011.05.07

33. Nishino T, Kobayashi A, Yokogawa H, Mori N, Sugiyama K. Changing indications and surgical techniques for keratoplasty during a 16-year period (2003-2018) at a tertiary referral hospital in Japan. Clin Ophthalmol. 2019;13:1499-1509. doi:10.2147/OPTH.S214515
34. Tan DT, Janardhanan P, Zhou H, et al. Penetrating keratoplasty in Asian eyes: the Singapore Corneal Transplant Study. Ophthalmology. 2008;115(6):975-982. doi:10.1016/j.ophtha.2007.08.049

35. Mendes F, Schaumberg DA, Navon S, et al. Assessment of visual function after corneal transplantation: the quality of life and psychometric assessment after corneal transplantation (Q-PACT) study. Am J Ophthalmol. 2003;135(6):785-793. doi:10.1016/S0002-9394(02)02278-X

\section{Publish your work in this journal}

Clinical Ophthalmology is an international, peer-reviewed journal covering all subspecialties within ophthalmology. Key topics include: Optometry; Visual science; Pharmacology and drug therapy in eye diseases; Basic Sciences; Primary and Secondary eye care; Patient Safety and Quality of Care Improvements. This journal is indexed on PubMed

Submit your manuscript here: https://www.dovepress.com/clinical-ophthalmology-journal
Central and CAS, and is the official journal of The Society of Clinical Ophthalmology (SCO). The manuscript management system is completely online and includes a very quick and fair peer-review system, which is all easy to use. Visit http://www.dovepress.com/ testimonials.php to read real quotes from published authors. 